\section{(2) OPEN ACCESS}

\title{
Developing a theoretical marketing framework to analyse JUUL and compatible e-cigarette product promotion on Instagram
}

\author{
Ganna Kostygina (10 , ${ }^{1}$ Hy Tran, ${ }^{1}$ Lauren Czaplicki, ${ }^{2}$ Siobhan N Perks (1) , \\ Donna Vallone ${ }^{\circ},{ }^{3,4}$ Sherry L Emery ${ }^{(1)},{ }^{1}$ Elizabeth C Hair ${ }^{3}$
}

'Department of Public Health, National Opinion Research Center, Chicago, Illinois, USA 'Department of Health, Behavior and Society, Johns Hopkins University Bloomberg School of Public Health, Baltimore, Maryland, USA

${ }^{3}$ Schroeder Institute, Truth Initiative, Washington, DC, USA

${ }^{4}$ College of Global Public Health, New York University, New York, New York, USA

\section{Correspondence to} Dr Ganna Kostygina, Public Health, National Opinion Research Center, Chicago, Illinois, USA;

kostygina-anna@norc.org

Received 19 October 2021 Accepted 22 December 2021
D Check for updates

(C) Author(s) (or their employer(s)) 2022. Re-use permitted under CC BY-NC. No commercial re-use. See rights and permissions. Published by BMJ.

To cite: Kostygina $\mathrm{G}$, Tran $\mathrm{H}$, Czaplicki L, et al. Tob Control Epub ahead of print: [please include Day Month Year]. doi:10.1136/

tobaccocontrol-2021-057120

\section{ABSTRACT}

Background E-cigarette promotion on social media coincided with the rapid growth of e-cigarette use among American youth, particularly with the increased JUUL pod vaporiser use. We examined commercial JUULrelated messages on Instagram to identify marketing appeals used to target users along the continuum of e-cigarette use; we mapped the appeals to existing theoretical marketing frameworks to better understand industry strategies.

Methods Hashtag-based keyword rules were used to collect JUUL-related posts from the Instagram application programming interface, 1 March-13 November 2018. Posts were classified as commercial or non-commercial. A combination of machine learning methods, keyword algorithms and human coding were used to characterise message themes in commercial posts.

Results Keyword filters captured 50817 relevant posts and $41 \%$ were commercial. Among commercial posts, $91 \%$ contained recruitment/trial-based appeals (eg, combustible tobacco cessation; product sampling; giveaways) and $71 \%$ featured reinforcement/addictionrelated appeals (eg, loyalty programmes). None of the commercial messages contained e-cigarette cessationrelated appeals and less than $25 \%$ mentioned quitting combustible tobacco as a recruitment appeal.

Conclusions Instagram posts featuring e-cigarette related marketing can increase exposure to persuasive messages encouraging e-cigarette trial and use particularly among susceptible youth. Stronger regulations are needed to prevent exposure to social media marketing among young social media users.

\section{INTRODUCTION}

The steady progress in reducing youth tobacco use in the USA was reversed by the recent exponential increase in adolescent e-cigarette use. ${ }^{1-3}$ Since 2014, e-cigarettes have been the most commonly used tobacco product among US middle and high school students. ${ }^{2}$ Following the introduction of higher nicotine-content e-cigarettes like JUUL, e-cigarette use rose dramatically from $11.7 \%$ in 2014 to $27.5 \%$ in 2019 among high school students and 3.3\%-10.5\% among middle school students. ${ }^{1}$

JUUL_a USB shaped, pod-based device-became increasingly popular since its launch in 2015, and the majority of youth who use e-cigarettes report JUUL as their usual brand. Additionally, JUUL and its many high-nicotine emulators are as or more efficient at delivering nicotine than conventional cigarettes, ${ }^{4}$ which makes them highly addictive, especially to nicotine-naive adolescents. ${ }^{5}$ In fact, an adolescent could reach the addiction threshold by inhaling the vapor generated by using a quarter of a JUUL pod per day. ${ }^{6}$ The earlier a person initiates nicotine use, the more likely they are to develop a severe and persistent addiction. ${ }^{57}$ Addressing the risk factors of youth tobacco use, including exposure to social media tobacco marketing, is essential to reducing rates of experimentation and progression to established use.

One risk factor for youth e-cigarette use is exposure to social media tobacco product marketing. ${ }^{8-10}$ Emerging research on social media marketing demonstrates that youth are frequently exposed to tobacco marketing on social media platforms, ${ }^{11}$ and never tobacco users who engage with social media marketing have greater susceptibility to use tobacco in the future. ${ }^{12}$ Youth consume social media at higher rates than the general US population, ${ }^{13} 14$ which can increase their exposure to targeted social media marketing shared directly by companies or shared indirectly through peer networks.

E-cigarette product vendors employ innovative methods of 'social selling', including social media native advertising and influencer promotion. These messages are currently unregulated, often target youth, feature branded merchandise and use celebrity or influencer promotion. ${ }^{15-17}$ In particular, the recent rise in JUUL's popularity among young people followed a considerable increase in JUUL product social media promotion.$^{16} 1819$ Content analyses of posts featuring JUUL-related terms revealed themes appealing to youth and novice users while trivialising addiction. ${ }^{19}$

Marketing strategies used to promote JUUL and the numerous JUUL-compatible or copycat devices that emerged following JUUL's success often parallel approaches used by major cigarette manufacturers to promote cigarettes to youth in the 1970 s and 1980s. Internal tobacco industry documents from this period reveal how tobacco companies used opinion leaders as trusted sources of information for youth. These opinion leaders recruited younger users and novices, promoting a cigarette brand to their followers or marketing smoking as a pathway to 'participation, togetherness, and membership in a group'. ${ }^{20-22}$

Effects of marketing on initiation, progression to heavier use and overconsumption

Due to the addictive properties of tobacco products, additional considerations are necessary to 
understand how tobacco companies' social media marketing strategies influence adolescents' trial, initiation and progression to heavier tobacco product use. Two theories of marketing provide valuable frameworks for analysing the types of tobacco marketing appeals that appear on social media.

According to Ehrenberg's ATR theoretical framework, ${ }^{23}$ three steps can account brand choice behaviour: (1) gaining awareness of a brand, (2) making a first or trial purchase and (3) being reinforced into developing and keeping a repeat buying habit. Awareness can be created through advertising. A trial purchase can arise for a variety of reasons: a cut price offer, unavailability of the consumer's usual brand, exposure to an advertisement or display, free samples or an attractive short-term promotion. Following trial, a repeat buying habit may develop, which is the crucial determinant of long-term sales and is primarily 'a matter of reinforcement after use'. ${ }^{23}$ Thus, repetitive advertising reinforces a habit. According to this framework, the 'consumer does not have to be persuaded to think of his habitual brands as better than others, but has to be reinforced in thinking of them as at least no worse'. ${ }^{23}$

The ATR theoretical framework, however, does not account for the specific effects of addictive products, such as tobacco, alcohol or other substances. A growing body of literature on addictive product marketing identifies marketing cues that influence users at varying stages of dependence and impact user progression along an addictive product consumption continuum. ${ }^{24-26}$ Furthermore, marketing cues can desensitise consumers to the risks and dangers involved with the use of potentially addictive products such as e-cigarettes or cigarettes.

While there are several frameworks that define the stages of addiction, ${ }^{24}{ }^{26-29}$ the underlying motivational factors fall into three major transitional stages: the transition from nonuse to 'near-addictive' use; the transition from 'near-addictive' to 'addictive' or regular use; and the transition from addiction or regular use to cessation or nonuse. In the first stage, message cues rely on peer influence and other forms of social reinforcement to increase the appeal of product trial. ${ }^{24}{ }^{28}$ For those in the transition from, many factors may contribute to transition from 'near-addictive' to 'addictive' use, such as stress relief or the sensual pleasure associated with use (ie, euphoria of getting high). ${ }^{29}$ Marketing cues that facilitate progression to the addiction phase relate to cravings and ways to manage consumption and product purchase. ${ }^{24}$ Finally, the transition from 'addiction' or regular use to cessation or non-use is a stage where messaging aims to encourage and support cessation. Cues include appeals to quit, communication about risks and messages that discuss the cost of addiction. ${ }^{24} 25$
A cross-walk of the ATR framework for product choice and consumption and the theoretical framework of addictive consumption based on stages of addition is presented in table 1 .

Understanding how addiction marketing cues (or cues encouraging regular use of potentially addictive products) are used in commercial e-cigarette social media content can provide meaningful insights for tobacco control, including the specific marketing strategies used to promote these products among novices and existing tobacco product users. In the current study, we synthesise Awareness, Trial and Reinforcement (ATR) and Addiction Marketing frameworks to examine JUUL-related messages on Instagram and classified posts based on addiction marketing cues that targeted users across the types of nicotine product marketing. The synthesised approach enables a fine-grained systematic analysis of brand promotion strategies, parsing out youth-oriented and new user-oriented messages and established user-oriented marketing and helps better understand attributes of these messages that can impact behaviour change and advance the evidence base for tailored intervention and regulatory efforts.

We focused our analysis on JUUL-related messages given its dominance in the class of pod-based nicotine delivery devices and the use of \#juul by compatible or competitive product brands to gain exposure on social media. Instagram was selected due to its popularity among youth and its relatively high engagement rate compared with other social media platforms. ${ }^{30}$ Results from this research can inform regulatory strategies to restrict or reduce commercial marketing on social media platforms.

\section{METHODS}

\section{Data acquisition and processing}

Data were retrieved from the Instagram application programming interface (API) using hashtag-based keyword queries through NUVI, Inc, a licenced syndicator of the Instagram firehose. ${ }^{19}$ To identify potentially relevant hashtags, we used Websta.me Instagram analytics website, prior literature and extensive knowledge of JUUL-related terminology and brands. Sample hashtag search terms included \#juul, \#juuling, \#juulvapor, \#juulpod, \#switchtojuul and \#juulgang. ${ }^{19}$ Our set of 54 JUUL-related hashtag-based search terms retrieved 144939 primary posts from 1 March 2018 to 11 November 2018. While the Instagram data included the body of the post and associated metadata, commentary or replies to the primary post were not included in the total message volume count due to the API restrictions for Instagram data acquisition. Therefore, the unit of analysis for this study was a primary Instagram post.

Table 1 Theoretical approach synthesis

\begin{tabular}{|c|c|c|}
\hline $\begin{array}{l}\text { Awareness, Trial and } \\
\text { Reinforcement (ATR) } \\
\text { Framework }\end{array}$ & $\begin{array}{l}\text { Stages of addiction } \\
\text { framework }\end{array}$ & Sample marketing strategies \\
\hline Gaining awareness of a brand & & $\begin{array}{l}\text { Marketing cues connecting lifestyle imagery with product use (including paid product placement, native advertising } \\
\text { and endorsements among influencers and lifestyle accounts); event sponsorship }\end{array}$ \\
\hline Making a first or trial purchase & $\begin{array}{l}\text { Transition from nonuse } \\
\text { to 'near-addictive' use }\end{array}$ & $\begin{array}{l}\text { Demonstrations of how to use the product, product sampling; product giveaways, branded merchandise giveaways, } \\
\text { discounts }\end{array}$ \\
\hline \multirow{2}{*}{$\begin{array}{l}\text { Being reinforced into developing } \\
\text { and keeping a repeat buying habit. } \\
\text { Regular users may or may not be } \\
\text { addicted to the product. }\end{array}$} & $\begin{array}{l}\text { Transition from 'near- } \\
\text { addictive' to 'addictive' } \\
\text { use }\end{array}$ & $\begin{array}{l}\text { Loyalty programmes to encourage more frequent purchases, honouring loyal users with coupons, larger unit } \\
\text { packaging, daily engagement messaging featuring shopping deals }\end{array}$ \\
\hline & $\begin{array}{l}\text { Transition from } \\
\text { 'addiction' to cessation } \\
\text { or nonuse }\end{array}$ & Appeals to quit addictive products or facilitating opt out options \\
\hline
\end{tabular}




\section{Data cleaning}

In order to assess whether captured posts were actually relevant to JUUL and related products and behaviours, and thus to accurately measure the volume of the social conversation about JUUL over time, we built a machine classifier (linear support vector classifier) that was trained using human coding. ${ }^{19}$ Two coders rated a random sample of 619 primary posts, stratified by week of posting. Coders evaluated JUUL-relevance based on both the visual and text components of each post. The classifier used text features and the human labels to identify patterns related to relevance. To assess the performance of the classifier, 10 -fold cross-validation was used. ${ }^{31-33}$ Classifier accuracy was 0.94; classifier recall (sensitivity) was 0.94 ; classifier precision (positive predictive value) was $0.95(\mathrm{~F} 1=0.94)$. The classifier precision approximates retrieval precision (ie, the proportion of the analytic data that are relevant to the topic of JUUL), which indicates the quality of the analytic data. ${ }^{34}$ Posts that were classified as irrelevant messages were removed to construct the final analytic data set, which included 50817 JUUL-relevant posts by 16323 unique users.

\section{Content analysis}

First, we classified posts in the analytic dataset $t$ as either 'commercial' or 'non-commercial'. Commercial posts were defined by presence of any of the following: branded promotional messages; URLs linking to commercial websites; usernames indicating affiliations with commercial sites; or user's account page consisting only of promotional posts. Non-commercial posts were those deemed non-sponsored; they reflected individual opinions or experiences or linked to non-promotional content. Two human coders rated a training sample of 1104 primary posts as commercial $(n=628)$ or non-commercial $(n=476)$. Resultant data were used to train a logistic regression classifier with L1 regularisation; 10 -fold cross-validation was applied to assess classifier performance. Classifier precision was 0.84 ; recall was 0.84 ; area under the curve was $0.89(\mathrm{~F} 1=0.84)$.

Only commercial posts were coded for message strategy based on a coding framework informed by the addiction marketing paradigm. ${ }^{16243536}$ We developed a language filter to categorise messages related to marketing strategies targeting individuals by type of marketing strategy along the continuum of addictive product use. We used this approach because the content categories were not mutually exclusive, and a post could be coded as featuring multiple strategies. The coding structure included: (A) awareness and trial targeting nonusers- to 'near-addicted' users (type 1), which featured cues in posts connecting lifestyle imagery with tobacco use (including paid product placement, native advertising and endorsements among influencers and lifestyle accounts); demonstrations of how to use the product; appeals to combustible cigarette smokers to switch to e-cigs; sampling; branded merchandise giveaways; or event sponsorship; (B) reinforcement or targeting existing customers who are potentially 'near-addictive to addictive' or regular users (type 2), which featured cues in posts promoting loyalty programmes to encourage more frequent purchases, honouring loyal users with coupons, reposts, shout-outs; larger unit packaging; or daily engagement posts featuring shopping deals; and (C) transition from addiction (or regular use) to cessation or non-use (type 3), which included posts featuring appeals to quit e-cigarettes or facilitating opt out options (eg, lowering nicotine content over time).

We next employed Targeted Topic Modelling (TTM) to identify the major topics discussed in posts across the three addiction

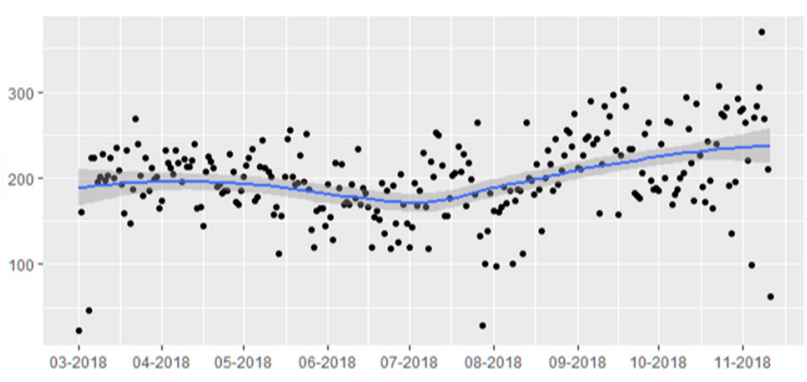

Figure 1 Amount of JUUL-related Instagram posts per day (1 March-11 November 2018).

marketing strategies. TTM is a supervised machine learning method, which is used to systematically discover topics of specific interest in a large corpus, enabling us to avoid 'suppression' of rare topics that might otherwise occur due to lower prevalence of these topics. We used R package 'mallet' to generate the top 20 topics. For each topic, weights were assigned to indicate the relative importance of terms featured.

\section{RESULTS}

Keyword filters captured 50817 relevant posts by 16323 unique users (figure 1) from March to mid-November 2018. The number of daily JUUL-related posts remained relatively stable over time (figure 1), with a slight decrease in the number of posts made during the month of July 2018 compared with other months. Approximately $41 \%$ of retrieved messages were commercial $(n=20873)$.

Among the commercial posts, 91\% $(n=19022)$ contained awareness and trial or nonuse or near-addictive use (type 1) appeals. These posts included messaging that connected lifestyle references with tobacco use; featured paid product placement or endorsements by celebrities and influencers. ${ }^{37-41}$ In addition, these posts offered free sampling or giveaway opportunities and promoted sponsored events. Approximately 25\% $(n=4818)$ of type 1 commercial posts contained content targeted towards users trying to quit combustible tobacco product use.

Nearly $71 \%(n=14838)$ of commercial posts featured appeals related to reinforcement or 'near-addictive to addictive' use (type 2). These included offers to buy products in bulk at a discounted rate, loyalty programmes to encourage more frequent purchases and honouring loyal users with mentions or shout-outs. Finally, none of the commercial posts contained reduced nicotine content appeals or addiction/regular use to cessation or nonuse promotion related to e-cigarette cessation (type 3 ).

Table 2 displays the top 20 topics and associated terms with highest probability to be part of each topic derived from the TTM analyses. Overall, 11 topics were associated with marketing related to awareness and trial. Topics included marijuana-related promotion, community or peer appeal, discussion of JUUL products and flavours, mechanisms to buy e-cigarettes online, starter kits, event promotion (eg, \#vapenights, \#goodvibes) and appeals to switch from combustible to electronic cigarettes. A total of nine topics were associated with marketing related to reinforcement and topics included chargers, brands, local vaping communities, discussion of nicotine and nicotine salt, product accessories (eg, \#vapeskin) and use with other combustible products, including marijuana. No topics were associated with e-cigarette or JUUL cessation (type 3 ).

Table 3 lists the top hashtags included in commercial posts by marketing strategy along the addictive product promotion continuum. The top six hashtags overlapped across groups; 
Table 2 Top 20 topics and associated terms from commercial JUUL-related Instagram posts by stage of addictive product use/marketing target group (1 March to 11 November 2018)

\begin{tabular}{|c|c|c|c|}
\hline Stage & Topic rank & Topic label & Text: top terms \\
\hline Type 1: awareness and trial & 1. & Marijuana-related cross-promotion & \#blunts, \#bongs, wax, sales \\
\hline Type 1: awareness and trial & 2. & Community/peer appeals & \#vapefriends, \#vapefam, \#vapelifestyle, \#vapecommunity, \#vapenation \\
\hline Type 1: awareness and trial & 3. & Juuling & \#juullife, \#juulgang, \#juulnation, \#juulmemes, \#juulwraps, \#juultricks \\
\hline Type 1: awareness and trial & 4. & Online stores/sales & online, store, vapour, \#cbdvape, \#highlife \\
\hline Type 1: awareness and trial & 5. & JUUL line extensions & silver, classic, flavours, mango \#cool, mint \\
\hline Type 1: awareness and trial & 6. & Smoker targeting & \#vapeordie, \#smoke, vaping, hookah, \#smoketricks \\
\hline Type 2: reinforcement & 7. & Chargers & jili, \#jilibox, box, rechargeable, \#collegedays, \#vapeaddict, \#doitforstate, charger, \#vapehappy \\
\hline Type 2: reinforcement & 8. & Pod vaporiser brands & \#suorin, \#suorindrop, \#bovaping, \#aspirebreeze, \#kanger, reviews, \#xfire, \#mrsalty \\
\hline Type 1: awareness and trial & 9. & E-commerce & \#21andover, ebay, price, \#ecig, prices, shout, sale, \#ecigwholesale \\
\hline Type 1: awareness and trial & 10. & CBD (cannabidiol) and marijuana & cbd, \#girlsvaping, \#cannabis, \#hemp, \#cbd, \#710, \#420 \\
\hline Type 2: reinforcement & 11. & Local user appeals & \#indyvape, \#vapeaholic, \#indianavape, \#vapingstyle, \#dripclub \\
\hline Type 2: reinforcement & 12. & Nicotine salt & \#nicotinesalt, \#nicotinesalts, \#saltnews, salt, nicotine \\
\hline Type 2: Reinforcement & 13. & Nicotine & Nicotine, addictive, $6 \%$, eonsmoke pods, \#collegelife, \#juice \\
\hline Type 2: reinforcement & 14. & Stig pods & \#stigpods, \#tricklyfe, \#teamcoolsmoketricks, @stigpods \\
\hline Type 1: awareness and trial & 15. & Kits & \#love, kits, starter, come, available \\
\hline Type 2: reinforcement & 16. & Mods and skins & \#vapemod, \#vapemods, \#vapeskin, \#vapewrap, camo, coils, decalkid, \#twistedcoilvapes \\
\hline Type 2: reinforcement & 17. & Combustible products & \#backwoods, \#pipes, Cubano, \#dailystoner, \#smokeyeyes, \#559stoners \\
\hline Type 1: awareness and trial & 18. & International promotion & Browse, \#vapeitaly, france, \#vapeindonesia, \#versace, \#louisvuitton, distributor \\
\hline Type 2: reinforcement & 19. & Cross-promotion & \#rollingpaper, \#lighters, \#cigs, \#wholesaleorders, \#paper, \#waterpipe, \#smoking \\
\hline Type 1: awareness and trial & 20. & Event promotion & \#goodvibes, \#halloween, \#nobadvibes, \#rock, \#punk, \#vapenights \\
\hline
\end{tabular}

however, hashtags for new user-related content (type 1) contained more JUUL brand references compared with the posts featuring addicted user-related content. Marketing associated with stage 1 or awareness and trial also contained hashtags related to JUULspecific community groups, while marketing associated with reinforcement (Type 2) featured more general non-branded, vape community-related hashtags. None of the commercial messages contained e-cigarette cessation-related appeals; however, the commercial posts potentially targeting new users (type 1) mentioned quitting combustible tobacco and other substances as a recruitment appeal and featured such hashtags as \#smoke $(\mathrm{n}=2722), \# 420(\mathrm{n}=1282)$ and \#detox $(\mathrm{n}=920)$.

\section{DISCUSSION}

The rapidly rising popularity of high nicotine e-liquids threatens to addict a new generation of youth. The current epidemic of e-cigarette use among American middle and high school students could erase decades of tobacco control progress. Social media posts featuring JUUL, JUUL-compatible or copycat product marketing can increase exposure to e-cigarette messaging and promote addictive product use among susceptible youth.

Our findings indicate that most of the promotional content (over 90\%) contained awareness and trial appeals to new and non-addicted users. A large proportion of content also featured reinforcement cues targeting potentially addicted e-cigarette users (over 70\%). These findings are consistent with prior evidence on marketing strategies used by tobacco companies to promote cigarettes among youth and new users, while at the same time appealing to existing users. ${ }^{20-22}$ In this study, we observed marketing messages targeted to non-users that contained references to JUUL brand and JUUL-specific community groups, which can enhance brand recognition among novices and connect the brand to lifestyle content via different JUUL-specific community posts. ${ }^{24}$ For reinforcement content targeting existing

Table 3 Top hashtags by content category (1 March-11 November 2018)

\begin{tabular}{|c|c|c|c|c|c|}
\hline Overall commercial content & Number of posts & $\begin{array}{l}\text { New user targeting/ } \\
\text { awareness and trial content } \\
\text { (type 1) }\end{array}$ & Number of posts & $\begin{array}{l}\text { Existing user targeting/ } \\
\text { reinforcement content (type 2) }\end{array}$ & $\begin{array}{l}\text { Number of } \\
\text { posts }\end{array}$ \\
\hline juul & 19302 & juul & 17634 & juul & 13927 \\
\hline vape & 13857 & vape & 12951 & vape & 10263 \\
\hline vapelife & 9578 & vapelife & 9487 & vapelife & 7499 \\
\hline vapenation & 7520 & vapenation & 7240 & vapenation & 5942 \\
\hline vapeporn & 6413 & vapeporn & 6185 & vapeporn & 5291 \\
\hline vapetricks & 5400 & vapetricks & 5190 & vapetricks & 4562 \\
\hline juulvapor & 5039 & juulpods & 4702 & vapelyfe & 4121 \\
\hline juulpods & 5039 & juulvapor & 4674 & vapefam & 3729 \\
\hline vapelyfe & 4438 & vapelyfe & 4370 & vapeon & 3542 \\
\hline juulnation & 4269 & juulnation & 4250 & juulvapor & 3444 \\
\hline
\end{tabular}


users, posts primarily mentioned the general, non-branded vape community, potentially fostering a sense of belonging to vaping communities and reinforcing a user's identity as a 'vaper'.

It is noteworthy that topics associated with targeting new users (type 1) included cross-promotion with marijuana products (potentially appealing to marijuana users), flavours (traditionally used to recruit new users of tobacco products), aspirational fashion or designer brand references, event promotion and appeals to combustible product users. Content associated with existing user marketing (type 2) included references to personalisation of JUUL products (eg, through use of decals or skins), alternative or compatible pod brands and references to increased nicotine use or overconsumption (modifying product strength: \#dripclub, \#vapemod, coils, \#twistedcoilvapes; daily use; vape tricks). Finally, no content mentions of e-cigarette cessation appeals were found within the study data. When considered against the overwhelming amount of new user and addiction or regular user-related marketing, this finding further highlights that JUUL and JUUL-like devices are marketed as tobacco products meant to recruit new users and maintain nicotine consumption.

Recent corporate social responsibility campaigns by tobacco and nicotine/e-cigarette product manufactures (eg, the Delivering a Smoke-free Future campaign by PMI), campaigns, promoting 'reduced risk' tobacco or nicotine products would imply that such campaigns would feature a category of marketing messages facilitating opt-out options of tobacco product use. ${ }^{42}$ However, we found no commercial messages that could be interpreted as providing opt-out options or that described a pathway to nonuse. Given the very limited presence of tobacco use prevention or tobacco use cessation messages on social media platforms, youth face a vastly disproportionate media environment.

\section{Limitations}

Generalisability of this study's findings reflects the nature of data collected through the Instagram API, which has been severely restricted since April 2018. Study findings may not generalise to other time periods, but they offer a cross-sectional representation of JUUL-related posts during a time period where the product was growing in popularity. The list of hashtags we used to retrieve JUUL-relevant posts was comprehensive but may not have included all JUUL-relevant hashtags and posts during this time period. Finally, since Instagram no longer provides data on the number of followers and level of influence at the account level, we were unable to identify the reach of specific messages. This study did not categorise the presence of paid social influencer accounts, potentially under-representing the amount of promotional posts. Future studies should investigate e-cigarette marketing strategies that target subgroups of non-addicted and addicted users, as well as the role of paid influencers on Instagram.

\section{CONCLUSIONS}

The tobacco industry has been adept at shifting strategies to avoid the restrictions imposed by the Master Settlement Agreement in the USA, as well as advertisement regulations existing in other countries, by taking advantage of viral marketing on media platforms popular among youth. Tobacco and nicotine product use on social media occupies a significant presence across these platforms. Tobacco companies successfully employ messaging strategies that raise awareness of products, encourage trial and reinforce use, providing a clear path from nicotine naivety to initiation and addiction but offer no support out of addiction. Tobacco control media campaigns can fill this messaging gap by offering messaging that describes a pathway out of addiction, providing at least some counterbalance to massive amount of highly effective tobacco industry promotional messages. While social media platforms attempt to restrict some forms of tobacco advertising and promotion, these policies are difficult to enforce and are frequently evaded because tobacco and nicotine product promotion on social media often occurs via influencer posts and organic word of mouth. ${ }^{43}{ }^{44} \mathrm{~A}$ policy that limits or eliminates branded accounts and influencer marketing of tobacco products could substantially reduce the likelihood that brand mentions and hashtags could gain virality in organic posts. Such efforts should be supported by tobacco control media campaigns to counterbalance the potential influence of social media marketing on addicting a new generation to tobacco use.

\section{What this paper adds}

- We examined JUUL-related content on Instagram to identify and quantify commercial messages featuring marketing cues targeting users across three stages of nicotine addiction (recruitment of non-addicted users, promotion of heavier use/ addiction and cessation).

- The majority of JUUL-related commercial posts contained recruitment-based appeals, such as product sampling, giveaways or combustible tobacco and other product cessation references, and a large proportion of posts also featured addiction-related appeals, including loyalty programmes. None of the commercial messages contained e-cigarette cessation-related appeals.

- Instagram e-cigarette related posts can increase exposure to persuasive messages promoting initiation and prompting or reinforcing progression to heavier use and overconsumption, particularly among susceptible youth who are present on social media. Stronger regulations can curb exposure to social media marketing among novices and young people.

Twitter Sherry L Emery @sherryemery and Elizabeth C Hair @ehairphd

Contributors GK, LC, SLE, DV and ECH together designed the study; HT and GK conducted data analysis; SLE, GK, LC and SNP contributed to data interpretation; GK wrote the first draft; SLE, LC, SNP, DV and ECH revised the draft; the final version of the paper has been reviewed and approved by all coauthors. GK acts as a guarantor.

Funding This study was funded by National Cancer Institute (R01CA248871) and Truth Initiative.

Competing interests None declared.

Patient consent for publication Not applicable.

Ethics approval This study does not involve human participants.

Provenance and peer review Not commissioned; externally peer reviewed.

Data availability statement Data may be obtained from a third party and are not publicly available. The data were obtained from NUVI, Inc, a licenced syndicator of the Instagram firehose.

Open access This is an open access article distributed in accordance with the Creative Commons Attribution Non Commercial (CC BY-NC 4.0) license, which permits others to distribute, remix, adapt, build upon this work non-commercially, and license their derivative works on different terms, provided the original work is properly cited, appropriate credit is given, any changes made indicated, and the use is non-commercial. See: http://creativecommons.org/licenses/by-nc/4.0/.

\section{ORCID iDs}

Ganna Kostygina http://orcid.org/0000-0002-8416-6168

Siobhan N Perks http://orcid.org/0000-0002-4982-6327

Donna Vallone http://orcid.org/0000-0001-9841-9333

Sherry L Emery http://orcid.org/0000-0001-9278-9990 


\section{REFERENCES}

1 Gentzke AS, Creamer M, Cullen KA, et al. Vital Signs: Tobacco Product Use Among Middle and High School Students - United States, 2011-2018. MMWR Morb Mortal Wkly Rep 2019;68:157-64.

2 Wang TW, Gentzke A, Sharapova S, et al. Tobacco Product Use Among Middle and High School Students - United States, 2011-2017. MMWR Morb Mortal Wkly Rep 2018;67:629-33.

3 Cullen KA, Gentzke AS, Sawdey MD, et al. E-Cigarette use among youth in the United States, 2019. JAMA 2019;322:2095.

4 Yingst JM, Hrabovsky S, Hobkirk A, et al. Nicotine absorption profile among regular users of a Pod-Based electronic nicotine delivery system. JAMA Netw Open 2019:2:e1915494.

5 Romer D, Duckworth AL, Sznitman S, et al. Can adolescents learn self-control? Delay of gratification in the development of control over risk taking. Prev Sci 2010;11:319-30.

6 Jackler RK, Ramamurthi D. Nicotine arms race: JUUL and the high-nicotine product market. Tob Control 2019;28:623-8.

7 Wellman RJ, Dugas EN, Dutczak H, et al. Predictors of the onset of cigarette smoking: a systematic review of longitudinal population-based studies in youth. Am J Prev Med 2016;51:767-78.

8 Hébert ET, Case KR, Kelder SH, et al. Exposure and engagement with tobacco- and E-cigarette-related social media. J Adolesc Health 2017;61:371-7.

9 Pokhrel P, Fagan P, Herzog TA, et al. Social media e-cigarette exposure and e-cigarette expectancies and use among young adults. Addict Behav 2018;78:51-8.

10 Sawdey MD, Hancock L, Messner M, et al. Assessing the association between e-cigarette use and exposure to social media in college students: a cross-sectional study. Subst Use Misuse 2017;52:1910-7.

11 Hébert ET, Case KR, Kelder SH, et al. Exposure and engagement with Tobacco- and E-Cigarette-Related social media. J Adolesc Health 2017;61:371-7.

12 Soneji S, Pierce JP, Choi K, et al. Engagement with online tobacco marketing and associations with tobacco product use among U.S. youth. J Adolesc Health 2017:61:61-9.

13 Anderson M, Jiang J. Teens, Social Media \& Technology 2018: YouTube, Instagram and Snapchat are the most popular online platforms among teens. Fully $95 \%$ of teens have access to a smartphone, and $45 \%$ say they are online 'almost constantly'. Pew Research Center, 2018.

14 Smith A, Anderson M. Social media use in 2018: a majority of Americans use Facebook and YouTube, but young adults are especially heavy users of Snapchat and Instagram. Pew Research Center, 2018.

15 Launchmetrics. The state of inflencer engagement in 2015.

16 Kostygina G, Tran H, Shi Y, et al. 'Sweeter than a Swisher': amount and themes of little cigar and cigarillo content on Twitter. Tob Control 2016;25:i75-82.

17 Knowledge@Wharton. A new marketing royalty: why digital Influencers are on the rise, 2017. Available: http://knowledge.wharton.upenn.edu/article/new-marketingroyalty-rise-digital-influencers/

18 Huang J, Duan Z, Kwok J, et al. Vaping versus JUULing: how the extraordinary growth and marketing of JUUL transformed the US retail e-cigarette market. Tob Control 2019;28:146-51.

19 Czaplicki L, Kostygina G, Kim Y, et al. Characterising JUUL-related posts on Instagram. Tob Control 2020;29:tobaccocontrol-2018-054824.

20 Teague CE. Research planning memorandum on some thoughts about new brands of cigarettes for the youth market. February 2, R.J.R.T.C., Inc. Bates No. 502987357502987368 .
21 Johnston, M.R.Y.S.P., trends, implications, and related demographic trends, 1981, 31 March (Minnesota trial exhibit 10,339)..

22 RJ Reynolds, Y.A.S.S.a.O., 1984, 29 February (Minnesota trial exhibit 12,579).

23 Ehrenberg ASC. Repetitive advertising and the consumer. J Advert Res 2000;40:39-48.

24 Martin IM, Kamins MA, Pirouz DM, et al. On the road to addiction: the facilitative and preventive roles of marketing cues. J Bus Res 2013;66:1219-26.

25 Carter BL, Tiffany ST. Meta-analysis of cue-reactivity in addiction research. Addiction 1999;94:327-40.

26 Tiffany ST. A cognitive model of drug urges and drug-use behavior: role of automatic and nonautomatic processes. Psychol Rev 1990;97:147-68.

27 Berridge KC, Robinson TE. Liking, wanting, and the incentive-sensitization theory of addiction. Am Psychol 2016;71:670-9.

28 Bozinoff L, Roth V, May C. Stages of involvement with drugs and alcohol: analysis of effects of drug and alcohol abuse advertising. Advances in Consumer Research 1989;16:215-20.

29 Substance Abuse and Mental Health Services Administration (US); Office of the Surgeon General (US). Chapter 2, The neurobiology of substance use, misuse, and addiction. In: Facing addiction in America: the surgeon general's report on alcohol, drugs, and health [Internet]. Washington (DC: US Department of Health and Human Services, 2016.

30 Elliott N, Parrish M, Colburn C. Use Instagram Now 2014.

31 Blei DM, Ng AY, Jordan MI. Latent dirichlet allocation. Journal of Machine Learning Research 2003;3:993-1022.

32 Evans MS. A computational approach to qualitative analysis in large textual datasets. PLoS One 2014;9:e87908.

33 Hastie T, Tibshirani R, Friedman JH. The elements of statistical learning: data mining, inference, and prediction. Vol. 2. New York, NY: Springer, 2009.

34 Kim Y, Huang J, Emery S. Garbage in, garbage out: data collection, quality assessment and reporting standards for social media data use in health research, Infodemiology and digital disease detection. J Med Internet Res 2016;18:e41.

35 Huang J, Kornfield R, Emery SL. 100 million views of electronic cigarette YouTube Videos and counting: quantification, content evaluation, and engagement levels of Videos. J Med Internet Res 2016;18:e67.

36 Huang J, Kornfield R, Szczypka G, et al. A cross-sectional examination of marketing of electronic cigarettes on Twitter. Tob Control 2014;23(Suppl 3):iii26-30.

37 Rock N' Roll It Vape N' Tobacco. TAG 5 people you know uses a juul!! 2018. Available: https://www.instagram.com/p/Bllsvo6lhFC/

38 The_Real_MJ_Campbell. My friend's new video for his product, 2018. Available: https://www.instagram.com/p/Bney9zBHIDX/

39 CatwalkELiquids. \#Repost @MiaKhalifa, 2018. Available: https://www.instagram.com/ p/BoAfWrsDJKM/

40 Vapefu_com. Damm it's that grape eon! ???????Now available at Vapefu.com @ eonsmoke TAG A FRIEND !!Click bio link !!. 2018. Available: https://www.instagram. com/p/BniHvwwH2zh/

41 Abrams N. Eon smoke is the Juul pod of the Future., in future sharks $2019 \mathrm{https}: / /$ futuresharks.com/eon-smoke-is-the-juul-pod-of-the-future/

42 PMI. Delivering a smoke-free future, 2019. Available: https://www.pmi.com/ourtransformation/delivering-a-smoke-free-future

43 Czaplicki L, Tulsiani S, Kostygina G, et al. \#toolittletoolate: JUUL-related content on Instagram before and after self-regulatory action. PLoS One 2020;15:e0233419.

44 Kong G. Tobacco promotion restriction policies on social media 2021. Under review in AJPH 2021. 